ISSN: $1130-3743$ - e-ISSN: 2386-5660

DOI: http://dx.doi.org/10.14201/teoredu2017291245272

\title{
EDUCACIÓN SOCIAL, DERECHOS HUMANOS Y SOSTENIBILIDAD EN EL DESARROLLO COMUNITARIO
}

\author{
Social education, buman rights and sustainability \\ in community development
}

\section{Éducation sociale, droits de l'homme et durabilité dans le développement communautaire}

José Antonio CARIDE Gómez

Departamento de Pedagogía y Didáctica. Facultad de Ciencias de la Educación. Universidad de Santiago de Compostela. Rúa Prof. Vicente Fráiz Andón, s/n-Campus Vida.15782 Santiago de Compostela.joseantonio.caride@usc.es

Fecha de recepción: enero de 2017

Fecha de aceptación: marzo de 2017

RESUMEN

El artículo sitúa sus aportes en una reflexión de naturaleza pedagógica y social acerca de los vínculos que se establecen entre la educación social, los derechos humanos y la sostenibilidad en el desarrollo comunitario. En este sentido, en clave histórica y prospectiva, pone énfasis en la necesidad de promover acciones educativas que, siendo congruentes con los principios de equidad y justicia, posibiliten construir una sociedad local-global más democrática, inclusiva y cohesionada.

Una expectativa de futuro que deberá concretarse en teorías y prácticas educativas en las que las comunidades locales asuman el protagonismo que les corresponde en sus propios procesos de desarrollo, con una visión alternativa de los modos de educar y educarse cotidianamente, respetuoso con los derechos humanos y ecológicos. Una línea de actuación que coincide con los compromisos adquiridos en el Programa de Acción Global sobre la Educación para el Desarrollo Sostenible, adoptado por la UNESCO, y la Resolución A/70/1 aprobada por la Asamblea General en 
2015, Transformar nuestro mundo: la Agenda 2030 para el Desarrollo Sostenible, garantizando un aprendizaje permanente para todos.

En este objetivo late una decidida, aunque no explícita, vocación pedagógicosocial: formar ciudadanos que, individual y colectivamente sean conscientes de su cometido en los cambios socioambientales, asumiendo las responsabilidades inherentes a los valores que sostienen la vida en toda su diversidad. La educación social y el desarrollo comunitario, al proyectar sus iniciativas en distintos tiempos y espacios sociales, permite ampliar las oportunidades formativas más allá del sistema escolar y de sus prácticas curriculares. La Educación Ambiental y Agenda Local 21 continúan siendo dos referentes principales para la reflexión-acción educativa y comunitaria.

Palabras clave: Educación Social; comunidad; derechos humanos; sostenibilidad; desarrollo comunitario; Educación Ambiental.

\section{SUMMARY}

The article places its contributions in a reflection of a pedagogical and social nature about the links that are established between social education, human rights and sustainability in community development. In this regard, in a historical and prospective key, it places emphasis on the need to promote educational actions that, being consistent with the principles of equity and justice, make it possible to build a more democratic, inclusive and cohesive local-global society.

A future expectation that must be confined to educational theories and practices where local communities assume the role they play in their own development processes, with an alternative vision to the ways of educating people and themselves on a daily basis, respectful of human and ecological rights. A line of action that coincides with the commitments made at the Global Action Programme on Education for Sustainable Development, adopted by UNESCO, and Resolution A/70/1 adopted by the General Assembly in 2015, Transform our world: the 2030 Agenda for Sustainable Development, guaranteeing lifelong learning for all.

In this objective beats a decisive, although not explicit, of a pedagogical-social vocation: to train citizens that, individually and collectively being aware of their role in socio-environmental changes, assume the responsibilities inherent to the values that sustain life in all its diversity. Social education and community development that, by projecting initiatives in different times and social spaces, allows formative opportunities to be expanded beyond the school system and its curricular practices. The Environmental Education and the Local Agenda 21 continue being two references main for the reflection-action educational and community.

Key words: Social Education; community; human rights; sustainability; community development; Environmental Education. 


\section{SOMMAIRE}

L'article situe sa contribution sur une réflexion de nature pédagogique et sociale sur les liens établis entre l'éducation sociale, les droits de l'homme et la durabilité dans le développement communautaire. Dans ce sens, selon une base historique et prospective, il met l'accent sur le besoin de promouvoir des actions éducatives qui, en étant, congruentes avec les principes d'équité et de justice, permettent de construire une société locale-globale plus démocratique, inclusive et cohérente.

Une expectative d'avenir qui devra se concrétiser par des théories et des pratiques éducatives dans lesquelles les communautés locales assument le rôle qui leur correspond dans leurs propres processus de développement, avec une vision alternative des manières d'éduquer et de s'éduquer au quotidien, respectueux avec les droits de l'homme et les droits écologiques. Une ligne d'action qui coïncide avec les engagements acquis dans le Programme d'action global pour l'Éducation en vue du développement durable, adopté par l'UNESCO et la résolution A/70/1 approuvée par l'Assemblée générale en 2015 Transformer notre monde: l'Agenda 2030 pour le Développement durable, en garantissant un apprentissage permanent pour tous.

Nous avons fait allusion a une vocation pédagogique-sociale décidée, mais non explicite, avec un objectif: former des citoyens qui, de façon individuelle et collective soient conscients de leur importance dans les changements sociaux et environnementaux et qui assument les responsabilités inhérentes aux valeurs qui soutiennent la vie dans toute sa diversité. Lorsque l'éducation sociale et le développement communautaire projettent leurs initiatives dans différents temps et espaces sociaux, elles permettent d'élargir les opportunités formatives au-delà du système scolaire et de son programme d'études. L'Éducation Environnementale et l'Agenda 21 Local continuent à être deux principaux référents pour la réflexion-action éducative et communautaire.

Mots clés: Éducation sociale; communauté; droits de l'homme; durabilité; développement communautaire; Éducation Environnementale.

\section{INTRODUCCIÓN, O LA NECESIDAD DE UN CAMBIO DE RUMBO}

El primer Día de la Tierra se conmemoró el 22 de abril de 1970. Fue entonces cuando en una de las naciones -Estados Unidos- que más ha contribuido al deterioro del Planeta, el senador demócrata Gaylord Nelson situó en el calendario la necesidad de crear una conciencia común sobre la destrucción progresiva de los ecosistemas naturales, amenazados por la superpoblación, la explotación y el agotamiento de los recursos, la contaminación y acumulación de residuos sólidos, el debilitamiento de la capa de ozono, las alteraciones climáticas, etc. Un conjunto de circunstancias a las que la economía convencional apenas había prestado atención, generando estilos de desarrollo y modelos de producción-consumo cada vez más nocivos para la conservación de la biodiversidad, hasta el punto de poner en grave riesgo la sostenibilidad de las actividades económicas y, por extensión, el 
logro de unas condiciones de vida dignas para toda la humanidad (Erias y ÁlvarezCampana, 2007; Mayor Zaragoza, 2009; Roca, 2016).

Pocos años antes, Rachel Carson (1962) ya advirtiera sobre las limitaciones del medio ambiente y su capacidad finita para absorber los contaminantes de los que se venía haciendo uso masivamente, en particular del Dicloro Difenil Tricloretano (DDT) y de otros pesticidas. A pesar del escaso conocimiento que se poseía sobre la trascendencia que podrían tener todos sus efectos colaterales, Carson no dudó en avanzar que la respuesta al problema residía en la «necesidad de sostenerse», adoptando estrategias que impulsasen un cambio de rumbo en las políticas públicas y en la gestión de los temas ambientales. No siendo una tarea fácil, como en muchos otros cambios de largo recorrido, pronto se invocará la necesidad de formar a la población en valores, actitudes y comportamientos proambientales, contribuyendo a que sea más consciente de los daños causados por la actividad humana, enfatizando la responsabilidad de los países industrializados y, al menos en sus indicadores socioeconómicos, de los que suelen tipificarse como más avanzados.

A las voces que con mayor o menor radicalidad posicionaron al movimiento ecologista ante la "crisis ambiental" se sumarían, desde los primeros años setenta del pasado siglo, distintos organismos y programas internacionales (fundamentalmente la UNESCO y el Programa de Naciones Unidas para el Medio AmbientePNUMA), insistiendo en la importancia de una educación, se dirá que "ambiental", que estimule la implicación de la población en la solución de los problemas ambientales. El Programa Internacional de Educación Ambiental, adoptado en 1975, que tuvo uno de sus momentos más álgidos con la celebración, en octubre de 1977, de la Conferencia Intergubernamental sobre Educación Ambiental, en Tbilisi (Georgia), sería uno de los principales baluartes en la expansión institucional de la Educación Ambiental, a la que mostrará su apoyo aunque sin cuestionar abiertamente el modelo de desarrollo dominante, optando por una visión pragmática y reformista orientada a restablecer los equilibrios entre las personas, la sociedad y su entorno. Una línea de actuación que se mantendrá, con altibajos, en las décadas posteriores hasta la irrupción de la «Educación para el Desarrollo Sostenible» (EDS), que inicialmente convive en las esferas gubernamentales de las Naciones Unidas con la "Educación Ambiental» (EA), pero a la que paulatinamente irá subordinando en las palabras y en los hechos.

Sin que nos detengamos en sus avatares, acerca de los que existe una amplia y heterogénea producción bibliográfica (Novo, 1998 y 2009; Caride y Meira, 2001; Mangas, 2003; Sato, Carvalho y otros, 2005; Gutiérrez y Pozo, 2006; González Gaudiano, 2008; Reyes y Castro, 2011), diremos que la participación directa de la población en la solución de los problemas ambientales y en la construcción de la sostenibilidad, con una visión crítica y prospectiva que propicie un giro radical en las prácticas del desarrollo conocido, no podrá hacerse sin una educación -ambiental y social- que las aliente en la vida cotidiana. Una misión de amplias avenidas pedagógicas y sociales, en las que adquiere un especial significado la adquisición de competencias y capacidades que precisan todas las personas para 
ser agentes activos en la sostenibilidad de su desarrollo individual y colectivo (Aznar y Ull, 2013). La profesora Murga-Menoyo (2015, 55) las resume en «una matriz competencial» básica, elaborada a partir de las cuatro competencias principales con las que la UNESCO, en los últimos años, propone afrontar sus retos: el análisis crítico, la reflexión sistémica, la toma de decisiones colaborativa y el sentido de la responsabilidad tanto hacia las generaciones presentes como a las venideras.

Los enunciados de estas competencias vinculan sus propuestas al Programa Mundial de Educación para el Desarrollo Sostenible que la Conferencia General de la UNESCO, celebrada en 2014, aprobado con dos grandes intenciones (UNESCO, 2014a): de un lado, reorientar la educación y el aprendizaje -concebidos como un proceso permanente, que ha de llegar a todas las personas- de modo que favorezcan la adquisición de los conocimientos, las competencias, los valores y las actitudes que se precisan para construir sociedades sostenibles y pacíficas, respetuosas con la diversidad cultural y el medio ambiente; de otro, reforzar el papel de la educación en todos los planes de acción, programas y actividades orientadas a este modelo de desarrollo, actuando a favor de la integridad del medio ambiente y de la viabilidad de la economía en un mundo más justo, tolerante, inclusivo y seguro.

La agenda de "la educación que queremos", trazada por la UNESCO (2014b) yendo más allá del año 2015 y del segundo de los Objetivos de Desarrollo del Milenio en su pretensión de asegurar una enseñanza primaria universal a todos los niños y niñas del mundo, se declara a sí misma ambiciosa, transformadora, holística... movilizando a todas las partes interesadas en la adopción de un enfoque integral. Considerando que el aprendizaje tendrá que extenderse a lo largo de toda la vida, apuesta por métodos pedagógicos y recursos didácticos innovadores, entre otros los que puedan proporcionar las tecnologías de la información y la comunicación.

Sus propósitos no son nuevos, aunque su mirada hacia el futuro incorpora una revisión crítica de los objetivos y de las metas que se formularon previamente -con sus logros y fracasos- en los tres grandes Foros Mundiales sobre Educación para Todos (Jomtiem, 1990; Dakar, 2000; Incheon, 2015) y en el que fuera proclamado como el Decenio de Naciones Unidas de la Educación para el Desarrollo Sostenible (2005-2014), como un asunto de todos para reducir las desigualdades y luchar contra la pobreza, fomentar la paz, combatir la marginación de las mujeres y las niñas, proteger el planeta del calentamiento global, promover y mejorar la educación de calidad... Concluido el Decenio, la Conferencia Mundial sobre la Educación para el Desarrollo Sostenible (EDS), celebrada entre el 10 y el 12 de noviembre de 2014 en Aichi-Nagoya (Japón), pretenderá dar continuidad a un programa mundial en cinco ámbitos de acción, a los que se considerará prioritarios para la EDs: el apoyo a las políticas, los planteamientos institucionales, los educadores, los jóvenes y las comunidades locales en distintos contextos, a los que nombran como «formales, no formales e informales». En la Declaración de la Conferencia, además de resaltar las especificidades y el conocimiento locales, las tradiciones y prácticas de las comunidades indígenas, se alude expresamente a la necesidad de respetar los principios 
universales que inspiran los derechos humanos, la igualdad entre hombres y mujeres, la democracia y la justicia social.

En este escenario, de futuros inciertos, coincidimos con Marta Tristão (2012) en que la cuestión ecológica puede -y debería - ser un factor que movilice la solidaridad planetaria, creando sinergias que articulen lo local con lo global, promoviendo un pensamiento crítico y transformador que transcienda las fronteras de los países. Por ello, siendo cierto que ninguna educación debe situarse al margen de la "emergente utopía de lograr una ciudadanía planetaria» (Novo y Murga, 2010, 179), también lo es que nunca podrá prescindir de las realidades de la vida cotidiana en las que cada persona se juega, día a día, su verdadera razón de ser. La Educación Ambiental en sus confluencias con la Educación Social, sigue siendo «un componente nodal no un simple accesorio de la educación, ya que involucra nada menos que la reconstrucción del sistema de relaciones entre personas, sociedad y ambiente", tal y como recuerda Sauvé $(1999,8)$.

Ambas -Educación Ambiental y Educación Social- tienen en la sostenibilidad un horizonte común (Iglesias y Meira, 2007, 25-26): la primera «será aquella que haga visibles las contradicciones de nuestra sociedad de hiperconsumo, los conflictos que surgen por causa de la hegemonía de una determinada cultura frente a otras, el contraste que se genera al coexistir sociedades opulentas y agrupaciones humanas sometidas a la marginación y a la extinción". En este sentido, añaden, cuando se concibe a la Educación Ambiental como una práctica educativa crítica y comprometida con la crisis socioambiental «comparte con una Educación Social que se sitúe en la misma sintonía paradigmática similares posicionamientos éticos, epistemológicos y metodológicos» (ibid., 26).

También en ellos ha situado Marco Marchioni (1994) la utopía posible de un quehacer comunitario democrático, que recupere los valores de la participación, la convivencia y la cohesión social ante los peligros que induce la fragmentación social, limitando o condicionando el alcance de iniciativas como las indicadas en la Agenda 21 Local. O, con una perspectiva complementaria, las propuestas contenidas en los tres Informes Mundiales GOLD I-III sobre la Descentralización y la Democracia Local, el primero referido al año 2008 y el último, con el auspicio de la Organización Mundial de la United Cities and Local Governments, el primer texto de referencia planetaria en el que se enunciaron los principios que constituyen la base de los fundamentos democráticos, constitucionales, jurídicos y administrativos de una gobernanza local descentralizada, en su interacción directa con la ciudadanía (Marcou, 2008).

2. ENTRE LOS DESEOS Y LAS REALIDADES DE LO QUE HEMOS DADO EN LLAMAR DESARROLLO SOSTENIBLE

Pensar el desarrollo no sólo en función de las necesidades del presente histórico, sino también en las que tendrán las generaciones del futuro, comienza por algo tan básico como considerar el progreso económico no como un fin en 
sí mismo, sino como un modo de armonizar el respeto a los derechos humanos -cuya Declaración Universal fuera aprobada el 10 de diciembre de 1948- con la puesta en valor de los derechos ecológicos, a pesar de no existir un documento que los mencione explícitamente. Ante los mensajes que objetan el crecimiento sin límites, las evidencias empíricas revelan que mientras la mayoría de las necesidades humanas son universales, los modos de satisfacerlas varían notablemente de unas personas a otras, dependiendo del contexto en el que se inscriban sus vidas, con implicaciones sociales y ambientales muy dispares.

Con todo, hubo que esperar a 1972 para que, en la Conferencia de las Naciones Unidas sobre el Medio Ambiente Humano, celebrada en Estocolmo entre el 5 y el 16 de junio (instaurando la primera fecha como el Día Mundial del Medio Ambiente), se adoptasen por vez primera decisiones orientadas a conciliar la protección ambiental con los derechos a un desarrollo humano más justo, económica y socialmente. La Conferencia, a pesar de la fuerte oposición de los Estados del Este y del Grupo de los 77 -integrado, desde 1964, por países en vías de desarrollo con el objetivo de apoyarse mutuamente en las deliberaciones de la ONU, llegando a ser en la actualidad más de 130-, aprobaría una declaración final de 26 principios y 103 recomendaciones, que tuvieron su primera concreción en el Programa de Naciones Unidas para el Medio Ambiente (PNUMA), en convergencia con el Programa de Naciones Unidas para el Desarrollo (PNUD), creado en enero de 1965.

Marcando un punto de inflexión en la política internacional, al vincular las soluciones a la crisis ambiental con la búsqueda de alternativas viables y duraderas a las crisis económicas que minaron, de forma reiterada, las ilusiones del "buen desarrollo», en 1983 mediante la Resolución 38/161 de la Asamblea General de Naciones Unidas, se creó la Comisión Mundial sobre el Medio Ambiente y el Desarrollo, que en abril de 1987 presentaría su Informe Nuestro Futuro Común (Comisión Mundial del Medio Ambiente y del Desarrollo, 1987), conocido con el sobrenombre de Informe Brundtland en reconocimiento a Gro Harlem Brundtland, en aquel momento primera ministra de Noruega, que presidió la Comisión que redactó el texto. Su principal mensaje se resume en la necesidad de acompasar el crecimiento económico con la sustentabilidad medioambiental, elevando las concepciones y prácticas del "desarrollo" a una categoría ética global (Sosa, 1994; Riechmann, 2004), tanto en clave humana como ecológica, mediando entre la urgencia y la utopía que ha desatado la crisis de civilización (Reyes y Castro, 2009); máxime cuando el uso y el abuso de los recursos de la Biosfera lejos de resolver las desigualdades las han ido agrandando, provocando impactos socioambientales que amenazan seriamente la supervivencia del planeta, ante los que ni la Pedagogía ni la Educación pueden inhibirse (Novo, 1998 y 2009; Colom, 2000; Limón, 2000; Caride y Meira, 2001; González Gaudiano, 2008; Mogensen, Mayer, Breiting y Varga, 2009; Ortega y Romero, 2009; Reyes y Castro, 2011; Aznar y Ull, 2013).

La Conferencia Mundial sobre Medio Ambiente y Desarrollo, celebrada en Río de Janeiro en 1992, popularizada como la "Cumbre de la Tierra", a la que dieron continuidad las Conferencias de la Naciones Unidas o Cumbres Mundiales sobre 
Desarrollo Sostenible (Johannesburgo, 2002; Río de Janeiro, 2012; y Nueva York, 2015), concentraron sus esfuerzos en anticipar «el futuro que queremos», la expresión con la que se tituló el documento final aprobado en Río+20. En su redacción, empleando un lenguaje lleno de ambigüedades, se asume -desde una perspectiva gubernamental- que la comunidad internacional está ante una oportunidad histórica para diseñar las vías de un mundo sostenible: combatiendo la pobreza y el hambre, fomentando la equidad social e incrementando la protección del medio ambiente de un planeta cada vez más poblado. En opinión de Murga-Menoyo $(2012,91)$, la Cumbre de Río +20 «parece a todas luces una ocasión desaprovechada para, con la autoridad y el impacto de este tipo de eventos, difundir un nuevo llamamiento hacia una renovación más profunda de la práctica educativa, aún muy lejos de promover la transformación personal y social que la sostenibilidad exige».

La que, oficialmente, pasará a ser identificada como la Agenda 2030 para el Desarrollo Sostenible, con el lema "Transformar nuestro mundo", de acuerdo con la Resolución aprobada por la Asamblea General de Naciones Unidas el 25 de septiembre de 2015, coincidiendo con el septuagésimo aniversario de la Organización, resumirá sus propósitos declarando que se trata de un plan de acción a favor de las personas, del medio ambiente y de la prosperidad, fortaleciendo la paz universal dentro de un concepto amplio de libertad. A lo que añade, una vez más, el reconocimiento de que la pobreza, en todas sus formas y dimensiones, representa el mayor desafío al que se enfrenta el mundo, constituyendo su erradicación un requisito indispensable para el desarrollo sostenible.

En este sentido, las esperanzas que se depositaron -y en buena medida frustraron- en los ocho Objetivos de Desarrollo del Milenio y sus 18 metas (20002015), cuyo relato se amplía en los 17 Objetivos de Desarrollo Sostenible y sus 169 metas (2016-2030), aspiran a dar una respuesta global a los retos que plantean, entre otros, la lucha contra la pobreza y el hambre; el logro de una educación de calidad para todos; procurar una vida saludable y la erradicación de enfermedades curables; el acceso a energías asequibles y el respeto al medio ambiente (y a los problemas ocasionados por el cambio climático); la producción y el consumo responsables; la equidad de género y el empoderamiento de las mujeres, o la promoción de sociedades más pacíficas, justas e inclusivas. El compromiso con el ideal común que anhela simbolizar el "desarrollo sostenible», se articula en tres dimensiones -económica, social y ambiental-, a las que se pretende abordar de forma equilibrada e integrada (Sanahuja, 2015). Una toma de postura que no resuelve las vaguedades que vienen lastrando sus paisajes semánticos al proclamar que, en términos de objetivos, se trata de un desarrollo que debe satisfacer las necesidades del presente, sin comprometer las que deban satisfacerse en el futuro; y en términos operacionales, posibilitar mejoras económicas y sociales respetando los ecosistemas naturales y la calidad del medio ambiente.

No obstante, aún prevalecen las concepciones de la sostenibilidad que reducen sus postulados a un mero tránsito hacia economías basadas en las energías renovables, que permitan cerrar los ciclos de materiales reutilizando los residuos 
como nuevos recursos. Tampoco puede eludirse el incesante cuestionamiento del vocablo "desarrollo sostenible», al que se tilda de retórico y contradictorio desde diferentes campos de las Ciencias Sociales y Ambientales (Caride y Meira, 1998; Bárcena, Ibarra y Zubiaga, 2000; Caride, Pereira y Vargas, 2007; Leff, 2008; MurgaMenoyo, 2012 y 2013; Aznar y U11, 2013):

a) En primer lugar, por tratarse de una noción ideológicamente interesada, sin una clara concreción en las prácticas económicas y políticas, de las que no se esperan cambios que estén a la altura de una cartografía civilizatoria que modifique los estilos de desarrollo, de producción, distribución, comercialización y consumo en los que nos hemos instalado en las últimas décadas, a los que la globalización está contribuyendo decisivamente, sumando seguidores a costa de ver fortalecidas sus ambigüedades semánticas. Tanto es así, que, de no problematizarse las propias bases del modelo socioeconómico y su culto a los mercados, «la viabilidad del desarrollo sostenible se ha convertido en uno de los mayores desafíos teóricos y políticos de nuestro tiempo... ante el imperativo de ecologizar la democracia, la tecnología y la moral» (Leff, 2004, 181). En opinión de Bárcena, Ibarra y Zubiaga $(2000,11-12)$ «desde los orígenes de este hoy universal concepto, su propia génesis y su evolución han resultado controvertidas y conflictivas", llegando a ser "el banderín de enganche de todos aquellos que han querido defender unas mejores relaciones entre economía y ecología. Entre desarrollo económico y sostenibilidad medioambiental».

b) En segundo lugar, porque combina dos términos cuyos orígenes han deparado una interpretación confusa sobre sus auténticas intenciones: el sustantivo "desarrollo", heredero del progreso y del crecimiento, al que en los análisis antropológicos, históricos, económicos y sociológicos le atribuyen una notable incidencia en la legitimación de las supuestas bondades del sistema capitalista neoliberal, obviando las desigualdades estructurales que definen los círculos de pobreza-riqueza, norte-sur, centro-periferia... en todo el mundo; y el adjetivo «Sostenible», utilizado por la Ecología para definir la capacidad de un determinado ecosistema para mantener la población de una especie sin disminuir sus posibilidades de subsistencia futuras; una "sustentabilidad" que venía referida a los sistemas biológicos y al mantenimiento de los recursos que se encuentran en su entorno a lo largo del tiempo. De nuevo el testimonio de Bárcena, Ibarra y Zubiaga (2000, 15) incide en el terreno de discusión que abonan el adjetivo y el sustantivo en la relación desarrollo-sostenible: la "relación de subordinación para con un sustantivo mayormente referido a cuestiones económicas y, por lo tanto, confundido y trastocado como crecimiento, ha supuesto la posible pérdida de su fecundidad innovadora, caminando hacia una práctica inactivada».

Todo ello explica, como señala Pilar Aznar (2010), que los intentos por definir el desarrollo sostenible se hayan cargado de controversias, siendo difícil conciliar 
las posturas que se decantan hacia un nuevo paradigma económico -de corte ecológico y social- que ajuste el desarrollo humano a los principios de la naturaleza, con las que siguen empeñadas en compatibilizar el equilibrio ecológico con el crecimiento ilimitado y la liberalización económica, regulada por leyes que aminoren los impactos ambientales. Como argumenta Martínez (2013), la crisis financiera y económica internacional del siglo xxI ha puesto en cuestión los valores del actual modelo de desarrollo basado en la filosofía capitalista neoliberal, cuyas nefastas consecuencias a nivel económico, político, social y ecológico han generado un modelo de sociedad en el que las desigualdades sociales han sido la nota dominante, contraviniendo los principios de la justicia social, la Carta de la Tierra y la Economía Social. Para Michael Redclift (2000, 37), que el desarrollo sostenible haya ganado aceptación, llegando a convertirse en un "proyecto global", no se compadece con el hecho de que «nuestra capacidad de encontrar soluciones se ha visto seriamente reducida por nuestra incapacidad de reconocer que somos prisioneros de nuestra propia historia».

\section{El DERECHO Al DESARROllo y a la EDUCACión COMO DERECHOS HUMANOS}

En la "nueva Agenda" se hace una alusión expresa a la Declaración sobre el Derecho al Desarrollo como una parte integrante de los derechos humanos (Rojas-Albonico, 1984; Pellet, 1990), a los que se cita reconociendo que los fundamentos del programa de acción son la Declaración Universal y los tratados internacionales que los formalizan en distintos ámbitos de actuación. Un derecho al desarrollo que se concretó en la Resolución 41/128 aprobada el 4 de diciembre de 1986 por la Asamblea General de Naciones Unidas, contra la que votaron, no obstante, varios países del eje «occidental» (Estados Unidos, Reino Unido, Alemania, Suecia..., entre otros); y en el que se aprecian dos vertientes -una individual y otra colectiva- de los designados como "derechos de tercera generación». Para Gómez Isa (2003, 44) merece la consideración de un «derecho-síntesis... que integra el conjunto de los derechos humanos, tanto en el ámbito nacional como internacional», reforzando su indivisibilidad e interdependencia ya que no cabe, añade, «un verdadero desarrollo sin una efectiva implementación de todos los derechos humanos» (ibidem).

Como se sabe, en la discutida y discutible tipificación generacional de los derechos humanos, los que se catalogan como de "tercera generación"-cuya titularidad es difusa y a los que se suele aludir como derechos colectivos o de la solidaridad- son aquellos que tratan de dar respuesta al variado elenco de transformaciones sociopolíticas, económicas, demográficas, culturales, tecnológicas, ambientales, etc., que se vienen sucediendo desde los años setenta del pasado siglo. Sin que estén suficientemente definidos, incluyen desde el derecho a un medio ambiente saludable, a la paz, al ocio, a la justicia transnacional, hasta el derecho a un desarrollo sostenible. De ahí que, como un modo de afrontar los riesgos e incertidumbres de las sociedades contemporáneas, se apele al valor de la 
solidaridad humana y a los principios que elogian la libertad, las virtudes cívicas, el bienestar o la calidad de vida en su totalidad.

El derecho a la educación, que la Declaración Universal de 1948 recoge en su artículo 26 como un soporte fundamental para un pleno desarrollo de las personas y el respeto a los valores cívicos (la libertad, la justicia, la igualdad, la comprensión, la tolerancia o la paz), tendrá en la Agenda 2030 un tratamiento que va mucho más allá de los enunciados contemplados en formulaciones previas -entre las que resulta paradigmática la que toma como referencia el segundo de los Objetivos del Desarrollo del Milenio, focalizado en el logro de una Educación Primaria Universal para todos- al estipular en su Objetivo 4 que deberá garantizarse «una educación inclusiva y equitativa de calidad y promover oportunidades de aprendizaje permanente para todos".

En este Objetivo la educación abre sus fronteras a distintos tiempos y espacios sociales, dentro y fuera del sistema escolar, prolongando las oportunidades de la educación y de lo educativo a lo largo de toda la vida. Una perspectiva, en la que subscribiendo los cuatro pilares básicos del aprendizaje -aprender a aprender, aprender a hacer, aprender a ser y aprender a vivir juntos- a los que se remite el Informe de la UNESCO sobre la educación para el siglo XXI, coordinado por Jacques Delors (1996), late una decidida vocación pedagógico-social, congruente con los postulados más estimables del desarrollo comunitario y una convivencia informada por los valores de la ciudadanía, desde la infancia hasta la vejez: una educación, se afirma, que elimine las disparidades de género y asegure el acceso igualitario a todos los niveles de la enseñanza y la formación profesional, otorgándole prioridad a quienes están en situación de vulnerabilidad, incluyendo las personas con discapacidad, los pueblos indígenas y los niños.

$\mathrm{Al}$ respecto, no debe pasarse por alto que el valor intrínseco de los derechos sociales reside en la igualdad de oportunidades: el derecho de cualquier persona a no ser excluida, siendo la educación el primer paso para que todos los individuos puedan construir libre e íntegramente su personalidad (Caride, 2009). Es en la educación, comenzando por la familia y continuando en las escuelas, los pueblos o las ciudades, donde residen los principales atributos para que las personas puedan dotarse de la capacidad de pensar, reflexionar y decidir por sí mismas, de un modo consciente y crítico. Son los aportes de la educación, cualesquiera que sean sus apellidos (escolar, social, familiar, etc.), los que permiten a las personas discernir cuánto y cómo se puede actuar con una visión transformadora que no contraríe el respeto al bien común y a las condiciones que sostienen la vida en toda su diversidad. En todo caso, siendo preciso advertir que sus logros no son espontáneos, ya que requieren de saberes que las habiliten cognitiva y emocionalmente en las múltiples e incesantes interacciones que los individuos establecen/establecemos con su/nuestro entorno.

Si en las instituciones escolares se trata de asegurar -lo que no implica certificar- que todos los alumnos adquieran los conocimientos teóricos y prácticos necesarios para promover el desarrollo sostenible (Aznar, 2003; Mogensen, Mayer, 
Breiting y Varga, 2009; Aznar y Ull, 2013), las opciones formativas que deben emprenderse tanto a través del currículum como de otras prácticas educativas deberán facilitar la adopción de estilos de vida sostenibles, la observancia de los derechos humanos, la lucha por la igualdad de género, la cultura de paz, la ciudadanía mundial o el aprecio por el diálogo intercultural. A las comunidades locales se les reconoce una especial capacidad para activar procesos de cambio e innovación en los que participen las familias, instituciones y entidades de titularidad pública o privada, para fomentar la cohesión comunitaria, además de inducir nuevos modelos de desarrollo rural y urbano, en los que podrán jugar un papel especialmente relevante el voluntariado, así como los centros y equipamientos socioambientales (Aznar y Ull, 2013).

Como ya constató la politóloga Elinor Ostrom (2011), la primera mujer que recibió -en 2009- el Premio Nobel de Economía, compartido con Oliver Williamson, son numerosas las comunidades que gestionan de forma eficiente y sostenible sus recursos basándose en las relaciones de confianza mutua que se establecen entre las personas, favoreciendo la cooperación frente a la competencia destructiva, haciendo compatible la necesidad de trabajar en acuerdos globales con las actuaciones en el plano individual y local. Las metas de un "buen" desarrollo no pueden construirse sin que se afirmen los mínimos comunes de una vida digna, que procuren a cada persona -en su entorno ambiental, familiar y social- los recursos que precisa para su autonomía en condiciones de libertad, equidad, justicia y democracia. No hay emancipación posible sin ellas.

Insistir, como lo hace Adela Cortina (2007), en observar los derechos humanos como exigencias éticas, separando esta circunstancia de cualquier mandato coyuntural o una disposición legal transitoria, refuerza sobremanera la naturaleza política y pedagógica de sus enunciados. De un lado, porque permite extender la condición ciudadana más allá de su reconocimiento normativo-legal, avalada por la universalidad de unos derechos que, por serlo, amparan la convivencia democrática e inclusiva; de otro, porque enfatiza el respeto a los derechos humanos como uno de los principales fundamentos de los valores cívicos y de la vida en común reconociendo las diferencias (la identidad en la diversidad y esta como una cualidad consubstancial a aquella), así como cualquier afán que permita avanzar en la construcción de una sociedad más justa y cohesionada, en lo local y en lo global, cerca y lejos. La preservación del planeta exige la satisfacción de las necesidades básicas de todos sus habitantes, que no es incompatible con el respeto a la diversidad biológica y cultural, como un logro «indisolublemente asociado a la necesidad de universalización y ampliación de los derechos humanos» (Vilches y Gil, 43), requerido por la necesidad de un planteamiento global que forje las condiciones de un futuro sostenible.

\section{EDUCAR Y EDUCARSE SOCIALMENTE: UNA PRÁCTICA COMUNITARIA COTIDIANA}

Toda educación es social, ya que necesaria e inevitablemente tiene la connotación de una práctica que se hace en sociedad, por, para y con la sociedad, en todas 
las sociedades (Durkheim, 1975). Los objetivos de la educación son sociales, como también lo son sus métodos y contenidos, en relación a los cuales la propia contextualización espacio-temporal del conocimiento y de las "acciones-intervenciones» educativas requieren de realidades, procesos, valores, recursos, procedimientos, interacciones, etc., en los que "lo social» es un componente tan substancial como ineludible, ya sea implícito o explícito.

De ahí que tanto en sus concepciones teóricas como en sus realizaciones prácticas, la Pedagogía Social como "discurso» teórico-práctico y la Educación Social como una práctica sustanciada teóricamente insistan en destacar el valioso potencial pedagógico, cultural y social de las realidades sociales cotidianas, a las que dan contenido iniciativas como las que se encarnan en las ciudades, comunidades y sociedades educadoras, las comunidades de aprendizaje, las escuelas-comunidad, los proyectos educativos de ciudad u otras/os con similares pretensiones, poniendo en valor una diversificada red de ámbitos y actores sociales. En ellas, el diálogo educación-comunidad siempre tendrá las connotaciones de una construcción pedagógica y social sustentada en la reciprocidad de las influencias que movilizan sus respectivas realidades (Caride y Pose, 2008, 37): "ya sea de forma intencional (por ejemplo, en los centros escolares) o de forma incidental, allí donde la cotidianeidad (en las familias, las calles y plazas, a través de los medios de comunicación social...), ejerce -con mayor o menor vocación educante- algún tipo de incidencia educativa, cultural o socializadora».

Para que la educación pueda participar plenamente de sus procesos debe ampliarse la visión que tenemos de la educación y de la sociedad, mirando sus circunstancias como una construcción "pedagógica» y "social» a la que hemos ido cargando de experiencias, concepciones y prácticas que han quedado atrapadas en los estrechos márgenes institucionales de la escolarización y/o de la educación reglada. Sobre todo, cuando la excesiva fijación en el currículum académico-escolar y en lo que acontece en el interior del sistema educativo y de los centros escolares -en la mal llamada educación formal- apenas trasciende los lindes que asimilan los procesos de enseñanza a la instrucción y los de aprendizaje a la adquisición de conocimientos, competencias, valores y actitudes mediante el estudio, el ejercicio o la experiencia pautada. Sin minusvalorar sus aportes a la formación científica, técnica y/o profesional de quienes son -o han sido- sus alumnos, al derecho a una educación para todos y a la igualdad oportunidades, la Educación Social plantea un doble desafío, más allá de los tiempos y espacios de la escolarización, e incluso de la institucionalización educativa, que resumimos en:

- Ampliar los espacios y tiempos educativos, favoreciendo una construcción más íntegra de la biografía cívica de cada sujeto y de sus procesos de socialización e interacción social, diversificando los agentes, los contenidos, las metodologías, las experiencias, los aprendizajes, los recursos, las iniciativas, etc., posibilitando que la educación pueda extenderse a todo el ciclo vital, entre la adaptación a las circunstancias del entorno y su transformación en el quehacer social cotidiano. 
- Procurar una mayor correspondencia entre las palabras y los hechos, especialmente cuando alude a universalizar la educación; una pretensión que, con frecuencia, se reduce al acceso a los niveles, modalidades o ciclos más básicos del sistema escolar, muy lejos lo que se espera que sea una efectiva universalización de las oportunidades de aprendizaje en las sociedades de la información y del conocimiento. No se trata de discutir la misión de la escuela, sino de afirmarla y repensarla en su diálogo con otras formas de educar-se para afrontar los retos socioeducativos del siglo XXI (March y Orte, 2014, 76): «una cuestión de necesidad, de obligación pedagógica y de compromiso ético"; sobre todo, añadimos, cuando acechan la vulnerabilidad, la marginación y la exclusión social (Gradaílle y Caride, 2016). Va más allá Jordi Longás $(2016,13)$ cuando afirma que «en ningún caso la supuesta crisis de la escuela significa la crisis de la educación, puesto que su papel es primordial para responder a las necesidades de desarrollo humano y, a la vez, a las crecientes situaciones de fractura social y exclusión». La crisis, sin obviar su importancia, induce a traspasar los límites del currículum para abrir la educación a procesos formativos más colectivos e integrales, en los que las comunidades locales sean uno de sus principales referentes contextuales.

Es en sus coordenadas donde imaginamos una educación social comprometida con un desarrollo humano alternativo, en el que las propuestas que se hagan sobre la educación para la ciudadanía y la sostenibilidad sean la respuesta, cuando menos, a tres retos en clave de derechos humanos: de un lado, profundizar en una conceptualización abierta y plural de la educación en/para el desarrollo sostenible, dando cabida a las distintas representaciones sociales que se suscitan en torno a los derechos y deberes de los individuos en sus prácticas cívicas; de otro, mejorar el análisis de sus propuestas y realidades, incidiendo en la comprensión e interpretación de las paradojas -actos de significado- que contienen sus respectivos relatos; finalmente, promover iniciativas que contribuyan a la formación en actitudes, valores, comportamientos, emociones, etc., en la cultura global de la sociedad-red, fortaleciendo la democracia, la ética del desarrollo y el desarrollo de la ética, dando prioridad a la gente (Sen y Kliksberg, 2007).

Los grupos primarios, entre los que se suele citar a las familias, pero también a otros ámbitos de socialización -las escuelas, el mundo laboral, las asociaciones o las comunidades locales-, son realidades vertebradoras de la experiencia cotidiana de la gente. La cotidianeidad, dirá Josep María Esquirol $(2015,56)$ alabando lo sencilla que es la vida, «es una especie de síntesis en la que cierta variación va apareciendo e integrándose»; la vida que acontece en la mayoría de los días, entre lo que ya se conoce y lo que es ligeramente nuevo. Es en ella donde, de un modo u otro, acaban proyectándose las necesidades y respuestas que busca la gente, otorgando al territorio y a la vecindad un papel clave, como contrapuntos necesarios a los impulsos de la globalización y del mundo desbocado que habitamos (Giddens, 2000; Maalouf, 2009): un mundo de todos y de nadie, en el que 
«ni siquiera el más poderoso está suficientemente protegido» (Innerarity, 2013, 44), aunque medie un abismo entre sus circunstancias y las de quienes sobreviven en la pobreza más extrema.

Lo cotidiano deviene en lo común, relacionando la civitas con la paideia para alentar nuevas formas de pensar lo educativo y lo social, aunque buena parte de sus propuestas filosóficas supongan retornar al pensamiento filosófico de Paul Natorp (1913) y al carácter fundacional de su obra Pedagogía Social, para darle al quehacer pedagógico-social un doble sentido: de un lado, el que elogia su inspiración comunitaria, como una educación que se hace en comunidad y hace a la comunidad; de otro, el que reivindica una comunidad que sea, en la acepción más sugerente del término, "pedagógica", en la que educar a los otros y educarse así mismos formen parte del mismo proceso.

Como interpreta Kuchenhoff $(1983,55)$, para Natorp -a quien se le reconoce la condición de "fundador» de esta corriente pedagógica- «era tan importante subrayar los componentes sociales (tanto de la educación para la comunidad como las influencias que condicionan la educación en la sociedad) frente a las tendencias individualistas, que llegaba a identificar los aspectos sociales determinantes de la práctica educativa con la pedagogía». Una Pedagogía Social que al paso del tiempo adquiere el estatus epistemológico de una disciplina científica y académica dotada de una identidad y entidad diferenciadas en el conjunto de los saberes y prácticas que nombra la educación (Petrus, 1997; Ortega, 1999; Núñez y otros, 2002; Pérez Serrano, 2003; Caride, 2005b; Úcar, 2016).

Para Vilanou $(2001,39)$ en su relectura de la Pedagogía Social en Natorp, cabe pensar que las relaciones educación-comunidad son inherentes a sus respectivas formas de ser: "Las exigencias de la educación radican en la comunidad de la misma forma que las de la comunidad en la educación. Siendo por tanto la comunidad la única que educa, se establece una clara conexión entre la educación y las diversas formas progresivas de comunidad: la familia, el municipio, el Estado, y finalmente, la humanidad». No es la educación de la persona aislada, sino la de quien vive en una comunidad, ya que entre ellas no hay separación posible. Ambas son las que permiten a los sujetos constituirse como seres sociales, desarrollando su identidad y sociabilidad acomodándolos a los códigos de una determinada cultura, proyectándolos en creencias, actitudes, comportamientos, valores, sensibilidades, etc., a través de los que se cristaliza su/nuestra complicada y compleja «adaptación» al mundo.

Los cambios que han venido experimentado las sociedades industrializadas, en las que las tecnologías de la información y la comunicación incorporan las paradójicas circunstancias de la «realidad virtual», acabarán otorgándoles nuevos significados a estos vínculos, aunque en lo fundamental prevalece el deseo de que la Pedagogía-Educación Social se convierta «en el nexo en torno al que han de promoverse estrategias que favorezcan las relaciones escuela-comunidad, con el fin de resituar la institución escolar en un proyecto integral de educación comunitaria» (Caballo y Gradaílle, 2008, 47). De ahí que coincidamos con March y Orte (2014) 
al señalar que la construcción de una nueva Pedagogía Social no puede darse al margen de las características de la sociedad actual, comenzando por la lucha contra las desigualdades, el fracaso y el abandono escolar prematuro; en definitiva, del papel inclusivo e integrador de una educación, escolar y social, de la que nadie duda sobre su caracterización como un derecho inalienable.

Enrique Leff atribuye a la Educación Ambiental -que nosotros ampliamos en la Educación Social- la posibilidad de recuperar el sentido originario de la noción de educere, abierta a un permanente diálogo de saberes, a los aprendizajes que emanan de la convivencia con los otros, a lo que no es cognoscible y pensable de antemano: "Aprender a dar su lugar al no saber y a la esperanza, a aquello que se construye en el encuentro cara-a-cara más allá de la objetividad y del interés» (Leff, 2008, 190), no para normalizar las ideas y los comportamientos, sino para posibilitar que se formen en sus responsabilidades transformadoras, conciliando la racionalidad pedagógica con la racionalidad ambiental y social.

Nombramos comunidades (pueblos, barrios, ciudades, etc.) que, además de poseer recursos, servicios, organizaciones, profesionales, etc., promueven dinámicas colectivas con las que dar respuesta a las dificultades y necesidades de las personas, comenzando por quienes -como sucede en la infancia o en la vejez, en la pobreza y en la exclusión- se encuentran en situación de mayor dependencia, riesgo o vulnerabilidad social. En este sentido, y para que la acción comunitaria no sea un concepto vacío, debe llenarse de contenidos teórico-normativos, estratégicos, metodológicos, operacionales, etc., que permitan alcanzar metas u objetivos viables. Sólo así las comunidades podrán observar su propio desarrollo como una forma de profundizar en las prácticas democráticas, dando respuesta a las necesidades de los sujetos en sus continuas interacciones con una sociedad-red y de redes (Longás, 2008). Para Ortega Ruiz (2009, 147) los referentes que proporcionan lo próximo, cotidiano y local son imprescindibles: es decir, "la necesidad de que los significados provengan de la cultura que rodea al individuo, para que éste se integre, sea parte de su propio mundo, se construya útil y relevante para lo suyo y los suyos"; aunque, advierte, "construir un mundo más justo puede, en un momento determinado, significar enfrentarse a lo local, y buscar lo universal, y en otro asumir que sin el calor de lo local no puede pensarse en lo universal» (ibídem).

Cuando todo parece globalizarse y uniformizarse no resulta extraño que las personas busquen en sus realidades más próximas nuevos modos de resistencia íntima ante los embates de la existencia, "para referirnos no tanto a las dificultades que el mundo pone a nuestras pretensiones como a la fortaleza que podemos tener y levantar ante los procesos de desintegración y de corrosión que provienen del entorno e incluso de nosotros mismos. Es entonces cuando la resistencia manifiesta un hondo movimiento de lo humano» (Esquirol, 2015, 10). Lo expresa Txus Morata $(2014,28)$ en su argumentación acerca de la Pedagogía Social Comunitaria como un modelo de intervención socioeducativa integral, señalando que «en momentos de complejidad social como el actual se requieren respuestas socioeducativas y culturales integrales que conecten redes y que miren y aborden la comunidad como un 
espacio de incorporación, de acogida y de acompañamiento a las personas, especialmente las más vulnerables y frágiles». También lo sugieren Civís y Riera (2007) cuando proponen entrelazar lo educativo y lo social en su propuesta de nueva pedagogía comunitaria, como un marco renovado para la acción sociopedagógica interprofesional. Siendo así, compartimos la idea de que las fragilidades vecinas sólo pueden afrontarse con nuevas dosis de vecindad: aquellas que traigan consigo otra mirada, posibilitando que la relación «derechos/deberes y ciudadanía/sociedad nos proporcione una nueva comprensión del proceso de socialización con sentido (de integración social) donde los mundos vitales, y los elementos de identidad y de sentido de las personas refuercen su responsabilidad» (Renes, 2006, 18).

\section{LAS COMUNIDADES Y SU DESARROLlO COMO CONTEXTO Y PRETEXTO EN LA CONSTRUCCIÓN DE LA SOSTENIBILIDAD}

Como diría Alain Touraine (1993), la comunidad se reivindica a sí misma como un modo de ser colectivo, sujeto de transformación de la historia y de la propia cotidianeidad; tanto o más que las familias y las escuelas, la comunidad es un tiempo-espacio para los aprendizajes de la vida social, del descubrimiento de los otros y del sentido colectivo de la vida (Marinis, Gatti e Irazuzta, 2010): un contexto en el que abundan los pretextos para construir la convivencia desde la educación y la educación desde la convivencia; o, expresado de otro modo, para que además de concebir las comunidades como un recurso pedagógico sea posible promover una pedagogía comunitaria en las que el desarrollo y la sostenibilidad sean dos de sus principales referentes.

El desarrollo local, como una forma de mostrar las identidades territoriales y sociales de las prácticas comunitarias, acostumbra a ser definido como un proceso de mejoras de la población, al que suelen vincularse tres áreas preferentes de actuación: la política-administrativa y sus procedimientos de descentralización; la económica, sustentada por los sistemas de producción y generación de riqueza locales; la socioeducativa y cultural, referida a las oportunidades creativas, formativas, artísticas y sociales que se construyen a través de la participación ciudadana y los procesos de enseñanza-aprendizaje en distintos contextos.

En este sentido, se constata como planteamientos ideológicos, sociopolíticos y metodológicos que insisten en reivindicar el desarrollo social a partir de lo que es «común» a las personas -considerando aspectos tan diversos como el paisaje, la cultura, los sentimientos o las vivencias que se configuran en un determinado territorio- tratan de validar modelos y procesos de desarrollo comunitario en los que se enfatizan las posibilidades de la educación en el logro de tres objetivos principales (Caride, Pereira y Vargas, 2007):

- Avanzar en las posibilidades que ofrece promover el reencuentro de las comunidades locales consigo mismas, garantizando la supervivencia del territorio y de los colectivos sociales que lo habitan, incluyendo una 
adecuada disponibilidad de sus recursos naturales y el respeto a los valores que toman como referencia las diferentes manifestaciones del patrimonio artístico-cultural legado por las generaciones precedentes. Para ello se requiere compatibilizar las dimensiones locales con las internacionales, la visión micro con la macro, la sociedad civil con el Estado, la autoestima con la alteridad, etc. La sociedad y el territorio, en todas sus concurrencias, son los ejes que modulan la transición entre sus respectivas realidades hacia modelos de desarrollo ecológicamente sustentados (Rodrigues, 2006).

- Responsabilizar y comprometer a las comunidades locales en los procesos de cambio y de transformación social, confrontando sus problemáticas, necesidades y demandas con las posibilidades y limitaciones (geográficas, culturales, demográficas, infraestructurales, económicas, tecnológicas, etc.) de la realidad de la que forman parte, ampliando sus capacidades de iniciativa y de crítica sin que -por principio- se renuncie a las ventajas que ofrezca el conocimiento científico y la innovación tecnológica en la promoción de un desarrollo cada vez más autónomo y sustentable.

- Afirmar en cada persona su protagonismo como sujeto y agente de los procesos de cambio social, desde su entorno inmediato y con la perspectiva de una sociedad cada vez más interdependiente y globalizada.

Las prácticas socioeducativas que transitan desde lo local hacia lo global, además de ofrecer la oportunidad de contribuir al bienestar de las comunidades, deben hacer partícipes a las personas de los procesos de desarrollo que se promueven, reconociéndolos como sujetos de la acción y no como meros objetos de atención. No hay un auténtico desarrollo de las comunidades y/o para las comunidades que no se haga con y desde ellas. Lejos de desaparecer, con la globalización y un cierto auge del individualismo, se ha reavivado el interés por la comunidad, que para Delanty (2006) es esencialmente comunicativa, basada en nuevos tipos de pertenencia y de vínculos sociales.

Frente a un pasado histórico en el que los procesos de desarrollo comunitario tuvieron un sentido descendente (de arriba-abajo), desde los últimos años del siglo xx se ha afianzado la idea de que las actuaciones que se lleven a cabo nunca serán sostenibles si las propias comunidades locales no participan en la toma de decisiones, siendo los principales agentes de su propio desarrollo, en un sentido ascendente (de abajo-arriba), tanto en el análisis de sus problemas como en los modos de afrontarlos y resolverlos. Esta perspectiva, que coincide con los enfoques del desarrollo endógeno (Caride, 2001), apela al empoderamiento de las comunidades y a la descentralización de los mecanismos de poder, ayudando a contextualizar las prácticas educativas y sus aportes al desarrollo local. El "prisma contextual», dirá Murga-Menoyo $(2015,64)$, es el que permite dar «relevancia a la cultura local como fuente inspiradora del cambio por la sostenibilidad». En su opinión, y "desde esta perspectiva cabe considerar que el desarrollo sostenible ha de ser, por definición, endógeno; es decir, generado en cada caso desde el interior de las comunidades, 
organizadas para analizar sus propios problemas, buscar soluciones, potenciar al máximo sus posibilidades y elegir su camino».

Son abundantes las iniciativas que han puesto en valor los procesos colectivos y ciudadanos en la toma de decisiones orientadas a resolver los conflictos medioambientales. Con frecuencia, como ha sucedido en la recuperación del río Guadaira (en la localidad sevillana de Alcalá de Guadaira y en otras que se asoman a su cuenca), además de reivindicar el protagonismo de la población en sus actividades, fomentan la adquisición de conocimientos y el desarrollo de las competencias éticas, políticas y emocionales que asocian la protección del patrimonio ambiental y cultural a la tarea de «educar en la sostenibilidad comunitaria» (Pabón, 2016).

En otros casos, como el que relatan Ángela Barrón y José Manuel Muñoz (2015), haciendo uso de una metodología de investigación-acción, basada en el diálogo y la negociación, con un enfoque sociocrítico, sistémico y transdisciplinar, podrá conseguirse que determinadas iniciativas -aparentemente menores- como las que representan los huertos escolares, al integrar a la comunidad, lleguen a constituir espacios socioeducativos de gran valor educativo y social, dado que no sólo sirven para mejorar la acción educativa, sino también para promover una cultura social comprometida con la sostenibilidad; si a ello se une "la participación de entidades externas, cohesionadas en torno a un proyecto educativo compartido, se irá progresivamente conformando una red de colaboración comunitaria más amplia, que permitirá avanzar mejor y en beneficio de todos; convirtiendo la iniciativa en un huerto escolar comunitario» (Barrón y Muñoz, 2015, 222).

La participación, como un derecho y una práctica cotidiana, es consustancial al modelo pedagógico y social que proponemos en clave de desarrollo comunitario local, tanto como para poder afirmar que éste no será sostenible sin una implicación consciente y motivada de la gente. Una participación que, además de vitalizar la democracia, sea un «elemento constitutivo del desarrollo sostenible de una comunidad para influir en distintos grados en las esferas del empleo, de la educación, de las artes, así como para enriquecer los horizontes identitarios de un territorio» (Pose, 2006, 125); un territorio, dirá Jesús Vilar (2008, 275), al que será importante concebir como «una de esas unidades de acción donde se debe conjugar con sabiduría el conocimiento, la técnica y la sensibilidad", en el que las posibilidades son enormes, pero también los riesgos; tanto como para no dejar sólo en manos de la escuela un quehacer cívico tan estratégicamente significativo como el que representa la educación.

La dimensión participativa precisa de la actuación de diversas instancias, ya que ningún actor o agente social posee la capacidad ni la legitimidad necesarias para ofrecer respuestas integrales e integradoras ante la complejidad y heterogeneidad de los problemas sociales y ambientales del nuevo milenio. En este sentido, las actuaciones educativas que se promuevan deben orientarse hacia el fortalecimiento del tejido social comunitario y de los recursos endógenos del territorio, así como hacia la mejora y el fortalecimiento de las competencias y capacidades de las personas que lo habitan. 


\section{LA EDUCACIÓN AMBIENTAL Y LA AGENDA 21 LOCAL COMO REFERENTES COMUNITARIOS PARA LA SOSTENIBILIDAD Y LA EDUCACIÓN SOCIAL}

No concluiremos sin alentar y reivindicar la relevancia de la Educación Ambiental en los procesos de desarrollo comunitario y, tanto como sea deseable, con la sostenibilidad (Caride y Meira, 2001; Caride, 2006; Sato y Carvalho, 2008; Gutiérrez y Pozo, 2006; Novo, 1998, 2006 y 2009; Quiva y Vera, 2010). En este sentido, y aunque tanto las teorías y prácticas del desarrollo sostenible como las de la Educación Ambiental admiten una gran pluralidad de perspectivas, entre los enfoques tradicionales y los emergentes (García del Dujo y Muñoz, 2013), son muchas las iniciativas educativo-ambientales que comparten finalidades y principios básicos del Desarrollo Comunitario, comenzando por el fortalecimiento de la sociedad civil: dar un protagonismo real a los sujetos y a los grupos, dotarse de estructuras participativas, concebir la acción social y educativa como un proceso de democracia cultural, equilibrar las mejoras cuantitativas y cualitativas, favorecer la autonomía y la gestión endógena de los procesos...

Nombramos tareas y objetivos que, además de valorizar de forma integrada y duradera los recursos locales, insisten en la necesidad de comprometer a las comunidades locales (desde los poderes públicos hasta los movimientos asociativos, en diferentes marcos institucionales y políticos, etc.) con la sustentabilidad. Una línea de actuación especialmente relevante, de la que se han hecho eco algunas estrategias de Educación Ambiental, contribuyendo a generar modelos, experiencias e indicadores para la sostenibilidad local en distintos contextos y realidades, en los que se afirma que "la participación tiene que ser la protagonista, o no logrará los efectos deseados" (Iglesias y Pardellas, 2008, 28).

La Agenda 21 Local, una expresión en la que se adjetiva y delimita el perfil comunitario de los compromisos que adquieren los organismos internacionales y los Estados con el desarrollo local en la Agenda-Programa 21, será uno de los principales instrumentos puestos a disposición de esa meta, derivada del capítulo 28 de la Agenda 21, que describe el cometido de las autoridades locales y de los municipios en los objetivos globales de la sustentabilidad, invitando a todos los sectores de la población a una participación activa y comprometida, justamente allí donde la democracia habilita a los ciudadanos para tomar decisiones sobre sus vidas, valorando las repercusiones directas que conlleva.

La Agenda 21 representa, en su concepción más sustantiva, un Plan de Acción mediante el que se pretende alcanzar a lo largo del siglo Xxi la sostenibilidad integral del Planeta, otorgándole a cada municipio -una de las formas en las que encuentran acomodo territorial y administrativo las comunidades locales- un lugar destacado en el impulso y gestión de su elaboración (Caride, 2010). Con esta perspectiva se admite que corresponderá a cada municipalidad determinar, en función de sus recursos y circunstancias sociodemográficas, institucionales y ambientales, los ritmos del debate e implantación de la Agenda 21 Local, así como los aspectos en los que incidirá prioritariamente, ya sea en el diagnóstico de sus realidades o en 
las actuaciones que emprendan a nivel municipal, en el sistema educativo o/y en el desarrollo local (Murga, 2006).

Este planteamiento ha tratado de ser congruente, en el marco europeo, con los acuerdos adoptados en la Carta de Aalborg por los representantes de sus gobiernos locales, reunidos en esta ciudad danesa en mayo de 1994 con motivo de la Primera Conferencia Europea de Ciudades y Pueblos Sostenibles. Los principios y acciones que subscribieron las autoridades municipales para avanzar hacia la sostenibilidad, ratificados y matizados posteriormente en las Conferencias de Lisboa (1996), Hannover (2000), Aalborg+10 (2004) y Sevilla (2007), acentuarán la necesidad de compatibilizar el sentido diferencial de cada Agenda Local 21 ("puesto que todas las ciudades son diferentes, debemos hallar nuestras propias vías de sostenibilidad»), con una actuación integrada y dialogada. Por ello, y más allá de las situaciones y prioridades que emanen de cada municipio, debería ser factible asegurar unos deberes mínimos, comunes a todos ellos, en los términos en los que están redactados en el documento de los Compromisos de Aalborg+10: un paso adelante significativo y coordinado, que ha de inspirar un futuro que identifique objetivos y establezca plazos para realizar un seguimiento de los progresos hacia su consecución.

Invitar a todos los actores locales a una participación activa, haciendo a cada ciudadano consciente y responsable de sus derechos en la gestión municipal de la sostenibilidad, constituye el primero de los compromisos declarados, abriendo el trabajo a diferentes organizaciones y agentes, a través de distintos mecanismos y procedimientos: foros cívicos, comisiones informativas, grupos de debate, asambleas, encuestas públicas, auditorías, etc. Retornamos a la participación como un derecho básico (Alguacil, 2008), que debe satisfacerse cotidianamente como un proceso con capacidad para transformar, implicar, articular, generar aprendizajes, comunicar o demandar espacios y tiempos proclives para la acción política, en las estructuras de los poderes públicos y en el seno de las redes cívicas.

Proporcionar incentivos a las prácticas participativas, conciliando la representatividad democrática de las autoridades locales con otras formas de democratizar la vida en común movilizando al conjunto de la ciudadanía, además de legitimar las Agendas 21 Locales como una opción política y metodológicamente viable para avanzar en la sostenibilidad local, permite socializar e interiorizar en cada persona los compromisos que adquiere con sus realizaciones, reforzando el rol que cada individuo y/o grupo social ha de desempeñar en la prevención, resolución o minimización de los problemas o conflictos socioambientales (Ramos, 2007).

Las Agendas 21 Locales son -o deben ser- un proyecto de los municipios y para los municipios, en el que se hagan visibles una serie de características o planteamientos básicos, como son: entender la sostenibilidad local desde una concepción global, contextualizada en cada realidad local; insistir en la voluntariedad y subsidiariedad de la implicación en sus procesos; promover la integración de todas las políticas municipales, con criterios de transversalidad; enfocar su elaboración desde una concepción abierta a las contingencias y a las responsabilidades 
compartidas; alentar sus tareas vitalizando el intercambio de experiencias; apostar por la participación ciudadana como una condición necesaria para al sostenibilidad cívica, política y ambiental; etc. Como ya expresara Hewitt (1998), sólo la implicación ciudadana y la participación en la gente en los ámbitos de la democracia local pueden romper los bloqueos y ampliar los horizontes más allá de los tiempos cortos y orientar, tanto como sea preciso, la vida en sociedad hacia la sostenibilidad. Un quehacer que la Educación Social hace suyo tanto como sepa y pueda.

\section{CONCLUSIONES}

En el Libro III de su Política, Aristóteles (2003, 129) definió explícitamente a la polis como "una comunidad de ciudadanos en un régimen político", en el que lo más importante son las personas, no el territorio, por muy decisivos o determinantes que sean los límites geográficos que trazan sus fronteras. El fin de la polis, con frecuencia equiparada a la idea de ciudad, no era otro que «alcanzar una vida justa y, por lo tanto, feliz» (López Barja de Quiroga, 2003, 41), para la que no basta con la reflexión teórica ni con la bondad de los argumentos, ya que se requiere su ejercicio.

Sean cuales sean las coordenadas en las que nos situemos, cuando se nombra a la Educación Social y a los Derechos Humanos, al Desarrollo Comunitario y a la Cultura de la Sostenibilidad, tratando de enfatizar sus aportes a la mejora del mundo, las palabras no pueden obviar la necesidad de su concreción en hechos, aunque -con frecuencia- las primeras estén lejos de proyectarse, tanto como sería deseable, en los segundos. Máxime cuando la recientemente aprobada Agenda 2030 para el Desarrollo Sostenible y sus 17 Objetivos insiste en la necesidad de impulsar un cambio de rumbo, progresivo y estructural, que garantice la inclusión y la equidad social, la justicia distributiva en el acceso a los bienes comunes y la sustentabilidad ambiental.

La tarea - a modo de una ecuación pendiente, que no supieron resolver las actuaciones promovidas en los Objetivos de Desarrollo del Milenio (2000-2015) - ya fue anticipada en la redacción del primero de los Principios de la Declaración de Río sobre el Medio Ambiente y el Desarrollo, al afirmar que las personas constituyen el centro de las preocupaciones relacionadas con el desarrollo sostenible, en plena armonía con la Naturaleza y con el conjunto de las condiciones que permitan atender las necesidades de las generaciones presentes y futuras. Los compromisos de los Estados con la sostenibilidad son consustanciales a los derechos humanos, a los que refuerza la idea ética de la dignidad: "Un valor común que los seres humanos nos hemos dado a nosotros mismos por el hecho de existir... un distintivo que hemos depositado en todas las personas para elevarlas y por extensión elevarnos nosotros también».

Cuando todo parece indicar que la política está más desbordada que nunca por los dictados de la economía y la fuerza de los mercados (incitados por las modalidades de consumo vigentes), recuperar la confianza en los derechos humanos forma parte de las urgencias del nuevo siglo. En su logro, a la Educación para 
Todos (EpT), al todo de la educación (desde la infancia hasta la vejez) y a todas las educaciones -entre otras, la que hemos dado en llamar «Educación Social»- les corresponde desempeñar un protagonismo clave: con respuestas preventivas y proactivas que asuman los desafíos que supone afrontar las incertidumbres y los riesgos inherentes a la globalización, a la revolución tecnológica, a la nueva arquitectura financiera internacional y sus impactos en la tensión riqueza-pobreza, a los cambios inducidos por las alteraciones climáticas, o a la pérdida de la biodiversidad y de los recursos comunes. En ellos, como hemos afirmado insistentemente, la ciudadanía local-global se juega mucho de su verdadera razón de ser.

Como se indica en el Informe Horizontes 2030: la igualdad en el centro del desarrollo sostenible (Naciones Unidas-CEPAL, 2016, 53), "la humanidad se encuentra ante un punto de no retorno: el impacto ambiental del estilo de desarrollo dominante pone en peligro su supervivencia y la de otras especies», mostrando dos singularidades que nunca antes se evidenciaron en la Historia: de un lado, su impacto no es solo local, sino que afecta a los bienes comunes (la atmósfera, los océanos, la biodiversidad...); de otro, que, por vez primera, hay una generación informada y consciente, a partir de datos científicos, de este impacto y de las amenazas que las acciones humanas representan para el medio ambiente. De todas las acciones necesarias para lograr el desarrollo sostenible y la cultura que lo promueva, pocas o acaso ninguna son tan importantes como las que proporcionará la educación, dentro y fuera de las escuelas, en las familias y las comunidades.

Sin duda, la universalización de los derechos continúa representando -cuando pronto se cumplirán ocho décadas de su Declaración- un reto de enormes dimensiones para el conocimiento, el pensamiento y la acción social, tanto en el plano individual -en la que hemos de afirmarnos como sujetos y no meros objetos de atención- como en el colectivo, comenzando por las realidades próximas y cotidianas; aquellas que, como sucede con los discursos y prácticas que invocan los renovados modelos de "desarrollo comunitario» (integral, integrador, local, endógeno, participado, etc.), no contrarían sino que reivindican una esperanzada relectura cívica de los vínculos que se establecen entre los Estados, las comunidades y las personas; o, si se prefiere, de la ciudadanía cosmopolita que habita en cada sujeto, al que se reconoce portador de los derechos que son el fundamento ético-político de la igualdad, la libertad y la fraternidad que agranda la vida en común.

La Educación Social, en su afán por contribuir a un aprendizaje permanente para todos, participa de los valores de la sostenibilidad asumiendo que el futuro depende de lo que hagamos hoy, en todo tiempo y lugar. De ahí sus convergencias con el desarrollo comunitario como una práctica que vaya más allá de las actuaciones concretas y puntuales, que dinamice la cooperación y el trabajo en red, los saberes compartidos en la interdisciplinariedad, poniendo en valor la importancia de la información y de la formación, con una visión alternativa de los modos de educar y educarse en sociedad, respetuosos con los derechos humanos y ecológicos. No sólo como una cuestión de principios pedagógicos y sociales, sino también de prácticas educativas alentadas por proyectos y métodos que siguen teniendo en la Educación Ambiental y 
en las Agendas 21 Locales algunos de sus principales referentes teóricos, normativos y cívicos, con posibilidades de aprendizaje inimaginables hasta hace pocos años.

\section{REFERENCIAS BIBLIOGRÁFICAS}

Alguacil, J. (2008) Espacio público y espacio político. La ciudad como el lugar para las estrategias de participación. Polis: Revista Académica Universidad Bolivariana, 20. Consultado el 22 de septiembre de 2016. http://www.revistapolis.cl/polis\%20final/20/art10.htm.

ARISTóteles (2003) Política. Santiago de Compostela, Universidad de Santiago de Compostela.

AZNAR, P. (2003) La escuela y el desarrollo humano sostenible: retos educativos a nivel local. Teoría de la Educación. Revista Interuniversitaria, 14, 151-183.

AZNAR, P. (2010) Educación para el desarrollo sostenible: reflexiones teóricas y propuestas para la acción. Edetania: Estudios y Propuestas Socio-educativas, 37, 129-148.

AZnar, P. y Ull, M. A. (2009) La formación de competencias básicas para el desarrollo sostenible: el papel de la Universidad. Revista de Educación, número extraordinario, 219237. Consultado el 30 octubre de 2016. http://www.revistaeducacion.mec.es/re2009/ re2009_10.pdf.

AZnar, P. y Ull, M. A. (2013) La responsabilidad por un mundo sostenible: propuestas educativas a padres y profesores. Bilbao, Editorial Desclée de Brouwer.

Bárcena, I.; Ibarra, P. y Zubiaga, M. (eds.) (2000) Desarrollo sostenible: un concepto polémico. Bilbao, Servicio Editorial de la Universidad del País Vasco.

BARRón, Á. y MuÑoz, J. M. (2015) Los huertos escolares comunitarios: fraguando espacios socioeducativos en y para la sostenibilidad. Foro de Educación, 13 (19), 213-239. Consultado el 25 de noviembre de 2016. http://forodeeducacion.com/ojs/index.php/fde/ article/view/380.

Caballo, M. B. y Gradaílle, R. (2008) La Educación Social como práctica mediadora en las relaciones escuela-comunidad local. Pedagogía Social. Revista Interuniversitaria, 15

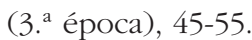

CARIDE, J. A. (2001) Las redes del desarrollo: conceptos, enfoques y perspectivas, en LucioVillegas, E. (ed.) Espacios para el desarrollo local. Barcelona, PPU, 17-61.

CARIDE, J. A. (2005) Las fronteras de la Pedagogía Social: perspectivas científica e bistórica. Barcelona, Gedisa.

CARIDE, J. A. (2006) Nombrar el desafío. El complejo territorio de las relaciones educaciónambiente-desarrollo. Trayectorias. Revista de Ciencias Sociales de la Universidad Autónoma de Nuevo León (México), año VIII (20-21), 11-24.

CARIDE, J. A. (coord.) (2009) Los derechos humanos en la educación y la cultura: del discurso político a las prácticas educativas. Rosario, Homo Sapiens Ediciones.

CARIDE, J. A. (2010) Políticas municipales y participación: la Agenda 21 Local. Janus. Anuário de Relações Exteriores, Lisboa, Universidade Autónoma de Lisboa-Público, 13, 88-89.

Caride, J. A. y MeIra, P. A. (1998) Educación Ambiental y desarrollo: la sustentabilidad y lo comunitario como alternativas. Pedagogía Social. Revista Interuniversitaria, $2\left(2{ }^{\mathrm{a}}\right.$ época), 7-30.

CARIDE, J. A. y MeIra, P. A. (2001) Educación Ambiental y Desarrollo Humano. Barcelona, Ariel.

Caride, J. A.; Pereira, O. M. y Vargas, G. (2007) Educação e Desenvolvimento Comunitário Local: perspectivas pedagógicas e sociais da sustentabilidade. Porto, Proferições. 
EDUCACIÓN SOCIAL, DERECHOS HUMANOS Y SOSTENIBILIDAD EN EL DESARROLLO COMUNITARIO

CARIde, J. A. y POSE, H. (2008) Comunidades que educan. Grial: Revista Galega de Cultura, XLVI (177), 36-41.

Carson, R. (1962) Silent Spring. Boston, Houghton Mifflin [primera edición en español, 1964).

Civís, M. y RierA, J. (2007) La nueva pedagogía comunitaria. Un marco renovado para la acción sociopedagógica interprofesional. Valencia, Nau Llibres.

Colom, A. J. (2000) Desarrollo sostenible y educación para el desarrollo. Barcelona, Octaedro.

Comisión Mundial del Medio Ambiente y del Desarrollo (1987) Nuestro futuro común. Madrid, Alianza Editorial.

CORTINA, A. (2007) Ética de la razón cordial. Educar en la ciudadanía del siglo XXI. Oviedo, Nobel.

Delanty, G. (2006) Community. Comunidad, educación ambiental y ciudadanía. Barcelona, Graó-SCEA.

DeLORS, J. (coord.) (1996) La educación encierra un tesoro: Informe UNESCO de la Comisión Internacional sobre la educación para el siglo XXI. Madrid, Santillana-UNESCO.

Durkheim, E. (1975) Educación y sociedad. Barcelona, Península.

ERIAS, A. y Álvarez-CAMPANa, J. M. (2007) Evaluación ambiental y desarrollo sostenible. Madrid, Pirámide.

EsQuirol, J. M. (2015) La resistencia íntima, ensayo de una filosofía de la proximidad. Barcelona, Acantilado.

GarCía DEL Dujo, Á. y MuÑoz, J. M. (2013) Enfoques tradicionales y enfoques emergentes en la construcción del marco teórico de la Educación Ambiental. Revista Española de Pedagogía, 71 (255), 209-226.

GIDDENS, A. (2000) Un mundo desbocado: Los efectos de la globalización en nuestras vidas. México, Ediciones Taurus.

GÓmez IsA, F. (2003) El derecho al desarrollo: entre la justicia y la solidaridad. Bilbao, Instituto de Derechos Humanos-Universidad de Deusto.

González Gaudiano, E. J. (coord.) (2008), Educación, medio ambiente y sustentabilidad. México, Siglo XXI Editores.

GRADAílle, R. y CARIDE, J. A. (2016) La accesibilidad en las realidades de la vida cotidiana: la Pedagogía social en la construcción del derecho a una educación inclusiva. Education Policy Analysis Archives-Archivos Analíticos de Políticas Educativas (AAPE-EPAA), 24, (91). Consultado el 10 de diciembre de 2016. http://epaa.asu.edu/ojs/article/view/2458.

GutiérRez, J. y Pozo, T. (2006) Modelos teóricos contemporáneos y marcos de fundamentación de la educación ambiental para el desarrollo sostenible. Revista Iberoamericana de Educación, 41, 21-68.

Hewitt, N. (1998) Guía europea para la planificación de las Agendas 21 Locales. Cómo implicarse en un plan de acción ambiental a largo plazo hacia la sostenibilidad. Bilbao, ICLEI-Bakeaz.

Iglesias, L. y Meira, P. A. (2007) De la Educación Ambiental a la Educación Social o viceversa. Educación Social. Revista de Intervención Socioeducativa, 35, 13-27.

Iglesias, L. y Pardellas, M. (coords.) (2008) Estratexias de Educación Ambiental: modelos, experiencias e indicadores para a sostenibilidade local. Vigo, Eixo Atlántico do Noroeste Peninsular.

InNERARITY, D. (2013) Un mundo de todos y de nadie: Piratas, riesgos y redes en el nuevo desorden global. Barcelona, Paidós.

Kuchenhoff, W. (1983) Pedagogía Social, en Diccionario de Ciencias de la Educación. Madrid, Rioduero, 35-39. 
LEFF, E. (2004) Racionalidad ambiental: la reapropiación social de la naturaleza. México, Siglo XXI-UNAM-PNUMA.

LeFF, E. (2008) Discursos sustentables. México, Siglo XXI Editores.

Limón, D. (2000) Pedagogía Ambiental: propuestas de cambio para una sociedad comprometida. Barcelona, PPU.

LONGÁs, J. (2008) Redes socioeducativas locales y desarrollo comunitario: Introducción. Cultura y Educación. Revista de Teoría, Investigación y Práctica, 20 (3), 263-265.

LONGÁs, J. (2016) Redes territoriales de acción socioeducativa, una apuesta por la innovación social colaborativa. Pedagogía Social. Revista Interuniversitaria, 28, 13-15. Consultado el 18 de diciembre de 2016. http://recyt.fecyt.es/index.php/PSRI/article/ view/44118/31283. DOI: http://dx.doi.org/10.7179/PSRI_2016.28.01.

López Barja de Quiroga, P. (2003) Prólogo, en Aristóteles Política. Santiago de Compostela, Universidad de Santiago de Compostela, 9-54.

MaAlouf, A. (2009) El desajuste del mundo: cuando nuestras civilizaciones se agotan. Madrid, Alianza Editorial.

Mangas, V.-J. (coord.) (2003) Educación Ambiental y sostenibilidad. Alicante, Universidad de Alicante.

MARCH, M. y ORTE, C. (2014) La recuperación de la institución escolar en el proceso de reconceptualización de la Pedagogía Social, en MARCH, M. y OrTe, C. (coords.) La Pedagogía Social y la escuela: los retos socioeducativos de la institución escolar en el siglo XXI. Barcelona, Octaedro, 57-83.

Marchioni, M. (2002) Las Agendas 21 y la evolución de los procesos de participación social: sostenibilidad ¿para qué y para quién? Sostenible?, 4, 73-82.

Marcou, G. (dir.) (2008) La descentralización y la Democracia Local en el Mundo. Primer Informe Mundial 2008. Barcelona, United Cities and Local Governments. Consultado el 23 de diciembre de 2016. http://www.cities-localgovernments.org/gold/Upload/ gold_report/gold_report_es.pdf.

Marinis, P. DE; GatTI, G. e IRAZUZTA, I. (eds.) (2010) La comunidad como pretexto: en torno al (re)surgimiento de las solidaridades comunitarias. Barcelona, Anthropos-Universidad Autónoma Metropolitana.

Martín Sosa, N. (1994) Ética ecológica. Madrid, Libertas.

MARTíNez, F. M. (2013) Educación, neoliberalismo y justicia social: una revisión crítica del desarrollo bumano desde la Carta de la Tierra y la Economía Social. Madrid, Ediciones Pirámide.

MAYOR ZARAGOZA, F. (2009) La problemática de la sostenibilidad en un mundo globalizado. Revista de Educación, número extraordinario, 25-52.

Mogensen, F.; Mayer, M.; Breiting, S. y Varga, A. (2009) Educación para el desarrollo sostenible: tendencias, divergencias y criterios de calidad. Barcelona, Graó-sCEA.

Morata, T. (2014) Pedagogía Social Comunitaria: un modelo de intervención socioeducativa integral. Educación Social. Revista de Intervención Socioeducativa, 57, 13-32.

Murga, M. Á. (coord.) (2006) Desarrollo Local y Agenda 21: una visión social y educativa. Madrid, Pearson-Prentice Hall.

Murga-Menoyo, M. Á. (2012) Río+20, recomendaciones a la educación. Edetania: Estudios y Propuestas Socio-educativas, 42, 91-106.

Murga-Menoyo, M. Á. (2013) Desarrollo sostenible. Problemáticas, agentes y estrategias. Madrid, McGraw Hill-unED. 
Murga-Menoyo, M. Á. (2015) Competencias para el desarrollo sostenible: las capacidades, actitudes y valores meta de la educación en el marco de la Agenda global post-2015. Foro de Educación, 13 (19), 55-83. Consultado el 6 de junio de 2016. http://forodeeducacion.com/ojs/index.php/fde/article/view/374.

NACIONES Unidas (2015) Resolución A/70/1, aprobada por la Asamblea General el 25 de septiembre de 2015: Transformar nuestro mundo: la Agenda 2030 para el Desarrollo Sostenible. Nueva York, Naciones Unidas. Consultado el 15 de noviembre de 2016. http://unctad.org/meetings/es/SessionalDocuments/ares70d1_es.pdf.

NACIONES UnidAS-CEPAL (2016) Horizontes 2030: la igualdad en el centro del desarrollo sostenible. Santiago de Chile, Naciones Unidas-Comisión Económica para América Latina y el Caribe (CEPAL). Consultado el 20 de diciembre de 2016. http://repositorio.cepal.org/ bitstream/handle/11362/40159/S1600653_es.pdf?sequence=4\&isAllowed=y.

Novo, M. (1998) La educación ambiental. Bases éticas, conceptuales y metodológicas. Madrid, Ediciones Unesco y Editorial Universitas.

Novo, M. (2006) El desarrollo sostenible. Su dimensión ambiental y educativa. Madrid, Pearson-UNESCO.

Novo, M. (2009) La educación ambiental, una genuina educación para el desarrollo sostenible. Revista de Educación, número extraordinario, 195-217.

Novo, M. y Murga, M. Á. (2010) Educación ambiental y ciudadanía planetaria. Revista Eureka sobre Enseñanza y Divulgación de las Ciencias, 7 (4), 179-186.

NúÑEZ, V. (coord.) (2002) La educación en tiempos de incertidumbre: las apuestas de la Pedagogía Social. Barcelona, Gedisa.

Ortega, J. (coord.) (1999) Pedagogía Social Especializada. Barcelona, Ariel.

Ortega, P. y Romero, E. (2009) La dimensión ética de la crisis medioambiental: propuestas pedagógicas. Teoría de la Educación. Revista Interuniversitaria, 21 (1), 161-178.

Ortega RuIZ, R. (2009) La educación y los derechos humanos ante los desafíos de la convivencia, en CARIDE, J. A. (coord.) Los derechos humanos en la educación y la cultura: del discurso político a las prácticas educativas. Rosario, Homo Sapiens Ediciones, 137-155.

Ostrom, E. (2011) El gobierno de los bienes comunes: la evolución de las instituciones de acción colectiva. México, Fondo de Cultura Económica.

PABÓN, M. (2016) Educar en la sostenibilidad comunitaria: la participación ciudadana en la recuperación del río Guadaira. Sevilla, Universidad de Sevilla (Tesis doctoral). Accesible en https://idus.us.es/xmlui/handle/11441/39523?show=full.

Pellet, S. (1990) Le droit au dévelopment, genèse et concept. Ginebra, Institut Universitaire de Hautes Études Internationales.

Pérez Serrano, G. (2003) Pedagogía Social-Educación Social: construcción científica e intervención práctica. Madrid, Narcea.

Petrus, A. (coord.) (1997) Pedagogía Social. Barcelona, Ariel.

Pose, H. (2006) La cultura de las ciudades: un quehacer cívico-social. Barcelona, Graó.

Quiva, D. y VERA, L. J. (2010) La educación ambiental como herramienta para promover el desarrollo sostenible. Telos. Revista de Estudios Interdisciplinarios en Ciencias Sociales, 21 (3), 378-394.

Ramos, J. (2007) Participación social y educación ambiental: los procesos participativos en las estrategias locales de sostenibilidad: un estudio de caso, en PUJOL, R. M. y CANO, L. (coords.) Nuevas tendencias en investigaciones en Educación Ambiental. Madrid, CENEAM, 83-109. 
REDClifT, M. (2000) El desarrollo sostenible: necesidades, valores, derechos, en BÁrCENA, I.; Ibarra, P. y Zubiaga, M. (eds.) Desarrollo sostenible: un concepto polémico. Bilbao, Servicio Editorial de la Universidad del País Vasco, 17-38.

Renes, V. (2006) Prólogo, en SubIRATS, J. (dir.) Fragilidades vecinas: narraciones biográficas de exclusión social urbana. Barcelona, Icaria, 9-24.

REYES, J. y CASTRO, E. (coords.) (2009) Urgencia y utopía frente a la crisis de civilización. Guadalajara-México, Universidad de Guadalajara.

Reyes, J. y CAStro, E. (coords.) (2011) Contornos educativos de la sustentabilidad. Guadalajara-México, Editorial Universitaria.

Riechamnn, J. (2004) Ética ecológica. Montevideo, Nordan-Comunidad.

RocA, J. (2016) Crecimiento contra medio ambiente. Barcelona, RBA.

Rodrigues, J. (2006) Sociedade e Território: Desenvolvimento Ecologicamente Sustentado. Oporto, Proferições.

Rojas-Albonico, N. (1984) Le droit au dévelopment comme droit de l'home. Berna, Peter Langs.

Sanahuja, J. A. (2015) De los Objetivos del Milenio al desarrollo sostenible: Naciones Unidas y las metas globales post-2015. Anuario CEIPAZ, 7, 49-84. Madrid, Instituto Complutense de Estudios Internacionales (ICEI).

Sato, M.; Carvalho, I. y cols. (2005) Educação Ambiental: pesquisa e desafios. São Paulo, ARTMED.

SAUvÉ, L. (1999) La Educación Ambiental entre la modernidad y la posmodernidad: en busca de un marco de referencia educativo integrador. Tópicos en Educación Ambiental, 1 (2), 7-25.

Sen, A. y Kuiksberg, B. (2007) Primero la gente: una mirada desde la ética del desarrollo a los principales problemas del mundo globalizado. Barcelona, Planeta.

Touraine, A. (1993) Crítica de la modernidad. Madrid, Temas de Hoy.

TRISTÃo, M. (2012) A educação ambiental e a emergência de uma cultura sustentável no cenário da globalização. Revista Internacional Interdisciplinar INTERthesis, 9 (1), 207-222. Consultado el 5 de octubre de 2016. http://dx.doi.org/10.5007/1807-1384.2012v9n1p207.

ÚCAR, X. (2016) Pedagogias de lo social. Barcelona, Editorial UOC.

unESCO (2014a) Declaración de Aichi-Nagoya sobre la Educación para del Desarrollo Sostenible. Conferencia Mundial. Aichi-Nagoya (Japón). Consultado el 20 de septiembre de 2016. http://unesdoc.unesco.org/images/0023/002310/231074s.pdf.

unesco (2014b) Más allá de 2015. La educación que queremos. Consultado el 20 de septiembre de 2016. http://www.unesco.org/new/fileadmin/MULTIMEDIA/HQ/ED/ED_new/ pdf/BEYOND2015-TheEdWeWant_Final_Brochure-SPA.pdf.

VAlLE, J. (2016) La capital del mundo es nosotros: un viaje multidisciplinar al lugar más poblado del planeta. Sevilla, CulBuks.

Vilanou, C. (2001) Introducción, en Natorp, P. Pedagogía Social: teoría de la educación de la voluntad sobre la base de la comunidad. Madrid, Biblioteca Nueva, 11-64 [original, en alemán, en 1899, existiendo una traducción al español, introducida por un texto del autor, en Ediciones La Lectura, en 1915].

Vilar, J. (2008) Implicaciones éticas del trabajo en red y la acción comunitaria. Cultura y Educación. Revista de Teoría, Investigación y Práctica, 20 (3), 267-277.

Vilches, A. y GIL, D. (2007) Emergencia planetaria: necesidad de un planteamiento global. Educatio Siglo XXI, 25, 19-49. 